\section{Del patrimonialismo a la competitividad: élites y sistema de valores en España}

Félix Ortega a configuración de las clases dominantes de una sociedad depende estrechamente de los procesos de cambios e innovación o del estancamiento social que en ella tienen lugar. La sociedad española moderna y contemporánea se ha caracterizado por la debilidad e insuficiencia de su proceso de modernización, que le ha llevado no sólo a incorporarse tardíamente a la modernidad, sino también a recuperar formas sociopolíticas ya periclitadas y que en la época de su vigencia en Europa tuvieron escasa fortuna en nuestro país. De algunas de las causas de esta singularidad histórica me he ocupado en otro trabajo, al que me remito (Ortega, 1992a). Aquí voy a tratar de explicar las razones que han hecho de la clase gobernante española un estamento con caracteres cuasi-feudales hasta fechas recientes, así como de los rasgos de la nueva clase surgida tras el advenimiento de la democracia.

\section{Un anacronismo histórico: La feudalización de la política}

a constitución de las élites del poder en la España Moderna no difiere, en principio, de los procesos que tienen lugar en otros países coetáneos. La progresiva transformación de la nobleza como grupo estamental y de status en otro claramente volcado a actividades lucrativas, supone la profunda renovación estructural llevada a cabo por el sistema de dominio propio del Absolutismo. De guerrera y basada en una economía del consumo, la nobleza deviene en grupo que civilizadamente practica el arte de la política (Elias, 1987) y se dedica a actividades económicas. La desvalorización del combate y de las funciones guerreras conduce a la nobleza, como ha señalado Maravall (1979, pp. 201 ss.), a mutarse en una clase gobernante que tratará de monopolizar el poder. Para ello reduce el número de sus efectivos, cohesiona internamente el grupo, se apropia de buena parte de la administración del Estado absolutista y acentua y fortalece los mecanismos de selección para pertenecer a ella. Mecanismos que ya no se fundan exclusiva o preferentemente 
en la nobleza de sangre ( $y$ por tanto en una modalidad de legitimidad carismática rutinizada), sino en demostrar una cierta competencia para el ejercicio de la función pública. De ahí, como muestra Kagan(1981, caps. 4 y 6), que Colegios mayores y Universidades quedasen reservados especialmente para los hijos de la aristocracia, que formaron una ujerarquía de letrados" que, en la mayoría de los casos, vino a confirmar, por via protomeritocrática, la adscripción social. De este modo, la incipiente burocratización del Estado queda neutralizada al ser absorbida por el mismo estrato social que venía disfrutando de privilegios en la dominación tradicional, al ser la cooptación el principal medio de acceso a los cargos públicos.

$\mathrm{Y}$ aunque durante todo el Antiguo Régimen los estratos intermedios y burgueses van adquiriendo una posición cada vez más definida, su vinculación a las tareas de gobierno es muy reducida y subalterna. A medida que se camina hacia la Edad Contemporánea, esta situación de apropiación de la Administración por parte de una aristocracia revitalizada es notoria. Al tiempo, como legítimo depositario de la tradición, este grupo se convertirá en un poderoso obstáculo para las políticas reformistas de los Austrias primero (piénsese en el Conde-duque de Olivares) y los Borbones después (Carlos III). Pero sobre todo, con este monopolio del poder, la nobleza originará profundos efectos sobre la estructura del mismo. En primer lugar, dará lugar a un tipo bien definido de dominación estamental; esto es, "determinados poderes de mando y sus correspondientes probabilidades económicas están apropiados por el cuadro administrativon (Weber, 1944, vol. I, p. 185). Todo ello implica, siguiendo una vez más a Weber, la permanente limitación a la libre selección de quienes han de formar el aparato administrativo, así como la apropiación de los cargos, de los medios y del poder político.

En segundo lugar, los sometidos a este tipo de dominación se convierten en servidores cuya forma de recompensa es la prebenda. Es decir, un intercambio no sólo desigual sino arbitrario, dependiente siempre de la libre voluntad del señor patrimonial.

En tercer lugar, el Estado no llega a convertirse en una instancia (relativamente) neutral y accesible y disponible a todos los ciudadanos, sino en una institución patrimonializada; esto es, poseida y usufructuada por el grupo que lo mono- poliza. Consiguientemente, la relación con el Estado sólo es posible a través de tal grupo, que, en definitiva, sustituye y suplanta a la institución misma. De este modo se genera la convicción de que la clase que gobierna es tout court el Estado. Al tratarse de un estrato legitimado a medias por la herencia y por la formación recibida (que se reserva a los privilegiados por nacimiento), tendremos un cuadro realista de lo que ha sido característico de la vida política española: Imposibilidad para dotarse de un Estado fuerte (muy diferente de los regímenes militares y dictaduras que ha conocido); vida política alejada de la opinión pública; bloqueo sistemático a una cierta renovación (no digamos ya "circulación") de las élites; constante dificultad para establecer un sistema de dominación legal-racional, $\mathrm{y}$, en fín, el alejamiento y despreocupación del ciudadano por los asuntos públicos (privatizados por esa minoría de ciclo largo en su dominio).

En cuarto lugar, este conjunto de factores expuesto vino a producir un resultado paradójico: España, que apenas tuvo en el Medioevo un sistema feudal, se va progresivamente feudalizando. El enfeudamiento se convierte en el elemento clave de la política, que permite a ciertos grupos estamentales apropiarse de poderes y derechos de mando en virtud de una iniciática investidura, primero personal, después convertida en tradicional. En consecuencia, la asociación política resultante se basa en una red de intercambios estrictamente personales sometidos al principio de la fidelidad (Weber, 1944, pp. 204 ss.).

Este entramado cristaliza de tal modo en la política española que más adelante, al intentarse una cierta liberalización de la misma por la Restauración canovista, el sistema se erigirá sobre una modalidad de feudalismo, el caciquismo. La esencia del mismo ( $y$ en este punto sigo el documentado estudio de J. Varela Ortega, 1977, pp.353 ss.), basado en organizaciones locales, es la negación de los partidos democráticos y la consagración del comportamiento parcial de la administración. Desprovisto del control de la opinión, contando con la desmovilización general y valiéndose del reparto de prebendas a un reducido núcleo de seguidores, el aparato del Estado quedaba enfeudado. Sólo servía para beneficiar a los amigos (la prebenda) y perseguir a los adversarios (la ley). Las funciones estatales lucrativas se privatizaban en manos de agentes fieles, y no se cumplía el principio de igualdad ante la ley. La relación del cacique con sus segui- 
dores es similar a la del patrón con el cliente, basándose ambas en el intercambio de favores personales. Se trata de una relación pragmática, en la que nada cuentan las ideologías. Y aunque el cacique solía ser propietario de tierras (no en vano el caciquismo tuvo éxito en una sociedad como la española, profundamente ruralizada), su singular posición dependía de la capacidad que tenía para controlar la administración en favor suyo y de sus clientes.

Curiosamente, la institución del caciquismo procede de la América precolombina. Aceptada y utilizada por los conquistadores, sirvió de intermediaria entre los indígenas y la administración colonial. Con este significado pasó a la metrópoli y sirvió para conformar el sistema de la Restauración (Varela Ortega, ibid, p. 354). Un dato más que confirma la hipótesis formulada en otro trabajo (Ortega, 1992a) acerca de la influencia negativa que la conquista de América tuvo para la evolución ulterior de la sociedad española.

Esta dominación estamental producirá diversos efectos estructurales que durante un largo ciclo histórico han frenado la innovación social. El más relevante de todos, desde el punto de vista de las élites, ha sido constituir una clase dirigente endogámica, que al suprimir los cauces de renovación y competencia, ha degenerado en un grupo insolvente y sólo capaz de realizar funciones directivas a condición de hacerlo en régimen patrimonial; en definitiva, ha monopolizado el poder. Lo que ha supuesto otra consecuencia no menor, a saber, que ha optado por fórmulas políticas monocráticas (en el sentido que a este término da Mastellone, 1990). Nada de extraño tiene, por tanto, que a esta clase dominante le fuesen achacados la mayor parte de los males de la sociedad, tal y como hizo Costa y el regeneracionismo.

Mas es sin duda Ortega y Gasset el que acierta a describir mejor la situación española surgida de semejante orden político. Utilizando una idea de Mommsen, piensa que la decadencia de una nación es fruto de la no incorporación a ella de todos los grupos sociales; este exclusivismo conduce al particularismo social, que no es otra cosa que un proceso de entropía que tiende a diluir la sociedad. Los "compartimentos estancos" (clases, grupos profesionales, regiones) han hecho de España un país desarticulado, "invertebrado" (Ortega, 1988, passim.). En lo que a mi juicio no es consistente el argumento orteguiano es en lo que concierne al diagnóstico del problema. La "ausencia de los mejores", de una élites rectoras aceptables, no es sólo el resultado de la masificación social, de su interna desvertebración; es sobre todo el efecto acumulativo de esas propias élites, que a través de las funciones de dirección, control y ejemplaridad han creado una sociedad a imagen y semejanza suya. Esto es singularmente importante a lo largo de todo el período histórico que he señalado anteriormente, ya que durante él es cuando se constituye en Europa esa realidad que llamamos "sociedad civil", cuya existencia es especular de la del Estado. Así, los defectos de esta sociedad a que alude Ortega son muy reales y de resultados funestos para nuestra historia contemporánea; mas ellos son un precipitado del tipo y la cualidad de unas clases dirigentes que han tratado de abortar sistemáticamente la existencia misma de la sociedad y del Estado como institución disponible para el conjunto de los ciudadanos.

La resistencia a abandonar esta posición monopolizadora de privilegios y oportunidades, junto con el resto de problemas sociales a que esta modalidad de dominación había dado lugar, provocaron el fracaso del primer intento consistente de cambio de la vida social y de sus dirigentes. Me refiero, claro está, a la II República. Ciertamente, como ya he escrito en otro lugar (Ortega, 1992a), también el régimen republicano adoleció de una clase política escasamente capacitada para hacer frente a la inmensa tarea que el régimen monárquico le legó. Pero fueren cuales fuesen sus carencias, el hecho más importante es que las clases dominantes tradicionales no le dejaron probar durante un tiempo razonable una nueva forma de ejercer el poder y de organizar la sociedad. Y esta es la razón primera del fracaso republicano: la resistencia conservadora a abandonar su posición patrimonialista en el Estado y la sociedad.

\section{La monocracia franquista: El retorno de los sacrosantos} poderes

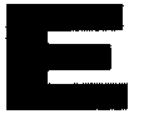

1 fin del enfeudamiento del poder que supuso el régimen republicano, apenas tuvo tiempo de constituir una renovada clase dirigente. El golpe militar y la subsiguiente guerra civil acabaron con ella; sus restos continuaron animando, ahora tan sólo como clase intelectual, la cultura de no pocos 
países latinoamericanos. El pronunciamiento, por lo demás, respondió a esa mentalidad exclusivista propia del patrimonialismo, que, convencido de que su "idea" es la única, no necesita persuadir a los demás: simplemente se limita a proclamar lo que cree, eliminando (física o políticamente) a los discrepantes. El constante descrédito de las vías políticas de organización social en nuestro país quizá se deba, como señalaba Ortega y Gasset (1988, pp. 60 ss.), a que los políticos representan todo lo contrario: la necesidad que cualquier grupo tiene de contar con los demás, esto es, de negociar y pactar y no de vencer. El franquismo, por el contrario, volvió a los métodos de acción directa: imposición de la voluntad absoluta de quienes habían detentado el poder durante largo tiempo

Al abolir la (débil y complicada) democracia republicana, el franquismo arrasó con todos sus elementos más genuinos: gobierno popular, instituciones representativas, igualdad de oportunidades, libertad de asociación, libertad de expresión y derechos civiles y sociales (que es el contenido de la democracia según Mastellone, 1990, p. 452). Posibilitó así el retorno de la monocracia cuya clase dirigente estaba constituida por los dos grandes pilares de la tradición conservadora: el Ejército y la Iglesia. A ellos se añadió, como una concesión de los tiempos, el partido único, la Falange. Esta sirvió, al menos durante un cierto tiempo, para facilitar el ascenso y promoción de sectores vinculados al bando vencedor, pero que por sus orígenes sociales no procedían de los estratos inveteradamente privilegiados. Una parte de la Falange sirvió, en definitiva, para esa legitimidad interclasista que todos los regímenes autoritarios de la época reivindicaron para sí.

Las características de esta élite, al menos hasta el momento que precede a la liberalización económica del Plan de Estabilización (1959), han sido analizadas por M. Jerez (1982, passim). Para acceder a cargos políticos era necesaria la vinculación a alguno de los tres grandes grupos constitutivos del régimen: el Ejército, la Iglesia y la Falange. Ahora bien, si se exceptua a los católicos, la peculiaridad del franquismo es que no prolonga sin más la dominación de las viejas clases monárquica y tradicional; antes bien, crea una nueva élite dirigente, que si bien tiene sus orígenes sociales en estratos afines a los de aquéllas, son por su edad y trayectoria producto del régimen mismo. Más en concreto, trátase de un grupo cuyo trasvase al poder se hace por mediación de su previa incorporación a los cuerpos altos de la Administración, y no simplemente por su adscripción a la nobleza o a la alta burguesía. A medida que esta nueva élite se afianza en el poder, su incorporación a la esfera económica - pública y privada- es progresiva e intensa. Y si bien el régimen toleró un cierto grado de permeabilidad en la configuración de su clase dirigente, por el cauce de la promoción en el partido único o en los sindicatos verticales, cada vez esta clase procedió a clausurarse y reproducirse endogámicamente.

La razón de este fenómeno de cierre es triple. En primer lugar, toda clase social que accede por primera vez al poder trata de monopolizarlo en detrimento de otra u otras posibles competidoras. En segundo lugar, en el franquismo se dió una superposición de los centros de extracción, que produjo una cierta amalgama de élites que dificultaba el ascenso de nuevos miembros no pertenecientes a alguno de los núcleos decisivos. En tercer lugar, las tensiones y los conflictos generados en una parte del bloque hegemónico, harán que el sistema político deposite una mayor confianza en el sector más fiel. En efecto, primero las disensiones entre los falangistas (unos más ortodoxos, otros más aperturistas y uliberales"); después entre éstos y los católicos, y por último la escisión dentro de estos últimos en varias corrientes, dejaron al Ejército como pilar fundamental del orden político. Su importancia numérica, su autonomía respecto del partido y su estructura disciplinada hicieron del mismo el continuo baluarte en la defensa del franquismo; lo que fue recompensado con una masiva presencia de militares en la élite del poder (político y económico). De hecho, muchos de los dirigentes que aparecían como civiles, procedían de alguno de los múltiples cuerpos que contenian cada uno de los tres ejércitos. Nada de extraño tiene que a las postrimerias del régimen y en los inicios de la transición democrática, las esperanzas de la reacción y los temores de la oposición se concentrasen en la actitud que adoptasen los militares.

Sin embargo, ello no quiere decir que el régimen estuviese socialmente aislado, ya que seguía contando con el apoyo y anuencia tanto de nuevos grupos católicos (piénsese en el importante papel jugado por el Opus Dei a partir de 1959), cuanto de jóvenes arribistas que utilizaban la vía político-sindical (por ejemplo el SEU) para ha- 
cer carrera. Pero si esto es cierto, no lo es menos que la clase dirigente así formada no podía representar a los nuevos grupos emergentes que el desarrollo económico de los años sesenta generaba. De igual manera que, sin proponérselo, el franquismo permitió un cierto grado de modernización social, en virtud de esta última posibilitó también la aparición de unas élites potenciales, que acabarian por sustituirle. Me estoy refiriendo en concreto a las transformaciones en la estructura estratificacional y al crecimiento de la burocracia estatal.

Por la primera, gracias sobre todo a la evolución de la población activa, cada vez más concentrada en los sectores secundario y terciario, surgen unas nuevas clases medias más aspirativas y una clase alta distante, en sus interereses y cultura, del conglomerado de fuerzas que apoyaba al régimen. Una clase, ésta última, paulatinamente constituida por empresarios, managers y profesionales liberales, que en escasa medida se reconocía en la legitimidad carismática y tradicional con que el régimen se presentaba. Además, la naturaleza de éste bloqueaba el ascenso a la política de estos nuevos dirigentes económicos y sociales.

De otro lado, a medida que el Estado turo que hacer frente a una realidad social más compleja a resultas del desarrollo, su aparato administrativo comenzó a crecer. Con ello, las aspiraciones de movilidad social surgidas en el cuerpo social encontraron una vía de realización en la burocracia. La reforma y ampliación de la Administración corrió pareja con la liberalización económica y los intentos de apertura al exterior: aquélla se modifica sustancialmente en los años 1957 (Ley de Régimen Jurídico), 1964 (Ley de Funcionarios Civiles) y 1965 (Ley de Retribuciones). Los criterios de racionalidad burocrática que tales modificaciones supusieron, se contradecian con el patrimonialismo político imperante, lo que causaba, entre otros efectos, una cierta desconexión funcional de ambos subsistemas. Pero, sin duda, la consecuencia más relevante es que el régimen se sirvió cada vez más de los altos cuerpos burocráticos para engrosar su clase política: según datos de M. Beltrán (en S. Giner, 1990 , pp. $326-327$ ), cerca del $80 \%$ de cargos de designación política, el $30 \%$ de procuradores y el $50 \%$ de consejeros nacionales del Movimiento eran funcionarios. A. de Miguel (1975, pp. 83 ss.) ha llegado a denominar "funcionariaton a la última etapa del franquismo, la que se inicia en 1973, para diferenciarla de las precedentes, la "azul" y la "tecnocrática». Aunque se trata de una simplificación, sin duda contiene una parte de verdad: el irresistible auge de los funcionarios en los finales del franquismo es un hecho cierto, por cuanto los grupos políticos organizados que habían sostenido al régimen, o habian desaparecido, o esperaban a la sucesión del mismo para incorporarse (redemocratizados) a los nuevos tiempos.

Pero también en esta Administración se desarrolla, de manera soterrada primero, más explícitamente después, un estrato que encuentra allí no sólo las posibilidades de ascenso social vedadas por la monocracia política, sino también una institución desde la que reivindicar la democracia negada. A este grupo podemos denominarle élite latente, y su contribución a la dirección de los acontecimientos posteriores al franquismo ha sido notable.

En resumidas cuentas, la Administración que se empieza a configurar en los años sesenta contiene, a mediados de la década siguiente está constituida por tres tipos de élites: una residual, identificada con el franquismo y asentada en los órganos más característicos del régimen; otra de transición, ya que colaboró, sino políticamente, al menos técnicamente con la dictadura (por ejemplo en los Planes de Desarrollo), y finalmente una tercera potencial, que sumergida en las sombras del anonimato funcionarial y sin vinculaciones con el régimen, se convertirá más adelante en una parte sustancial de la ucirculación de élites" que se produce en la década de los ochenta.

Por esta particular posición, la burocracia estatal sirvió para aliviar tensiones derivadas del autoritarismo político, al permitir un alto grado de movilidad social. En virtud de tal singularidad, la burocracia adquirió un conjunto de propiedades que ha incidido negativamente en su posterior funcionamiento. Así, en primer término, los altos cuerpos funcionariales habian asumido como propia una posición elitista, que bloqueaba la adecuada renovación y reforma de la Administración. Por tal motivo y ante la necesaria expansión burocrática, tuvo lugar un crecimiento desordenado y caótico de la misma, con la multiplicación de categorías (toda una miriada de "razas" y usubrazas", funcionariales o contratadas), de difícil acoplamiento funcional. Al tiempo, un rebrote del patrimonialismo condujo a que la Administración en su conjunto y el fun- 
cionario en particular, adoptasen el principio de la no responsabilidad. De todo ello se derivó una hipertrofia (con la secuela de su alto coste económico) y un cierto clientelismo (cooptación) notoriamente manifiesto en los altos cuerpos. Racionalizar este mastodonte era y sigue siendo complicado; sobre todo porque ello implica delimitar prerrogativas de sectores con poder y autodefinidos como "grupos de status". (Un análisis, quizá algo dramático, de este estado de cosas ha sido realizado por A. Nieto, 1984).

\section{Elites de transición.} Ascenso burocrático y predominio de lo público

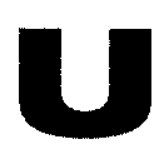

no de los retos principales de todo régimen autoritario es asimilar los cambio de su entorno, asi como mantener o renovar las fuentes de su legitimidad. En el caso español, además, la derrota del fascismo había aislado al sistema político como para que este pudiera sobrevivir sin hacer concesiones en algunos dominios. Estas se acumularon preferentemente en el aumento de las oportunidades del debate público, eliminando el derecho a participar directamente en la elección de sus representantes. El régimen inició así, sin saberlo, una de las secuencias de transición a la democracia que, para Dahl (1990 pp. 42 ss.), ha sido históricamente de mayor estabilidad. "El proceso de iniciación más propicio para una poliarquía -sostiene Dahl- es el que transforma las estructuras y formas hegemónicas, previamente legitimadas, en formas y estructuras aptas para la competencia política evitando de este modo divisiones persistentes y dudas sobre la legitimidad del nuevo régimen, compartidas por grandes sectores de la población» (ibid., p. 52), A la muerte del dictador, el régimen, que ya había perdido su legitimidad basada en el ideario católico-falangista, no tenía otro apoyo que el del único sector que como parte integrante de la clase gobernante le seguia siendo fiel, el Ejército. Ante sí no tenía más que dos alternativas: aumentar la represión, o tolerar las plenas liberalización y representación. Los intentos intermedios (Ley de asociaciones, "espíritu del 12 de febreron) resultaron infructuosos. $\mathrm{El}$ régimen, que para asimilar algunos de los cambios producidos tuvo necesidad de un cierto margen de liberalización, carecía de atractivos para incorporar a sus filas a las nuevas generaciones; incluso le eran desafectas fracciones de la antigua clase dominante. De manera que lo que parecía una compacta élite, era en realidad frágil e inconsistente. Como ha señalado Dahrendorf $(1974, \mathrm{p}$. 248) contra Mosca, no siempre quien domina está mejor organizado que los dominados. Quizá debido al postulado paretiano de que cuanto más cerrada es una élite, y la del franquismo ya hemos visto que lo era en grado sumo, antes degenera.

El franquismo, además, había promovido nuevos intereses (económicos y de expectativas de promoción) que era ya incapaz de salvaguardar. Cambio de intereses que implicaba una profunda remodelación de la estructura de clases: frente a una sociedad rural, con una pequeña y débil clase media, la realidad de ahora se erigía sobre una amplia clase media urbana, un proletariado industrial y una clase alta adquisitiva antes que poseedora (Weber). Con este panorama, en el que la autoridad monocrática había perdido sus dos pilares de sustentación claves, el de los intereses materiales y el de la legitimidad, se hacía necesaria una renovación del personal dirigente. ¿Cómo y en qué medida se produjo tal relevo?.

De entrada y durante la denominada transición democrática, tienen lugar dos procesos de movilidad política de signo diverso: un adescenson o repliegue de los sectores hasta entonces hegemónicos, y un "ascenso" o afloración de grupos de interés hasta entonces políticamente latentes pero que ahora se tornan manifiestos. Quienes formaban parte destacada e ideológicamente comprometida del régimen (militares, sindicalistas y del Movimiento) ceden en poco tiempo su posición de privilegio y pasan a ser un grupo de presión contra la naciente democracia. El desmoronamiento de la vieja élite es, por tanto, relativamente rápido y escasamente traumático; estamos ante un grupo claramente agotado en sus posibilidades políticas. Por el contrario, la promoción de nuevos sectores o de grupos que habían colaborado con el régimen para después distanciarse de él, resultó ser extremadamente rápida.

Ahora bien, esta circulación de doble sentido no debe confundirse con una acirculación de éli- 
tes) en sentido estricto. Mientras dura la transición, en realidad se produce una amalgama de nuevas y viejas élites, que, a medio plazo, condujo inexorablemente a la disolución de los restos de la vieja clase que consiguieron sobrevivir a la muerte del autócrata y al ascenso de una renovada clase dirigente. La amalgama fue fruto de la convergencia de diversos factores:

(1) Los intereses económicos privados que el crecimiento de los últimos lustros del franquismo había promovido. Se trataba del capital financiero y especulativo que pretendía no perder la posición preeminente alcanzada, así como aumentar sus oportunidades en una economía que necesariamente tendría que abrirse al exterior y apoyarse más en la libre iniciativa. Por tal razón encontramos entre los políticos del momento a representantes de la banca y los sectores empresariales más dinámicos; asimismo fueron incorporados otros a través de la designación real para ocupar puestos en el Senado del período constituyente. Es también ahora cuando estos intereses privados se dotan de auto-organización, constituyendo asociaciones que jugarán un destacado papel en la sociedad civil

(2) Los sectores liberales y menos comprometidos del franquismo. Grupos heterogéneos, pero todos ellos caracterizados por una trayectoria de total dedicación a la política, si bien no en las instituciones represivas. Sus posibilidades de mantener y acrecentar la posición lograda (puesto que en la mayoría de los casos no habían dado el salto al mundo de las actividades privadas lucrativas) dependía enteramente de asegurar su propia transición ventajosa al nuevo régimen. $\mathrm{Su}$ posición política táctica fue la "reforma".

(3) La oposición democrática y los sindicatos, cuyas expectativas políticas y de intereses son en este momento muy altas, al contar con una infraestructura organizativa cuasi tolerada y con fuerte apoyo exterior. Libres de toda culpa de colaboración con la dictadura, pero conscientes de que no podian enfrentarse abiertamente con la fuerza coactiva de ella, optaron por una discreta actitud de "ruptura", que no era otra cosa que una tactica para negociar con los restos del aparato franquista descritos en el párrafo precedente.

(4) La Iglesia, que de brazo ideológico del viejo régimen había pasado a distanciarse de él hasta el punto de contribuir activamente a su pérdida de crédito. Esta institución, además, al- bergaba en su seno algunos grupos organizados que si bien no desembocaron en un partido politico (opción desechada por la jerarquía eclesial del momento), fueron embriones importantes de algunos de los partidos políticos fundamentales de la democracia española.

Si estos fueron los factores que desde el punto de vista de las organizaciones sociales contribuyeron a amalgamar sectores distintos de diversas clases dirigentes (en decadencia o emergentes), hay otro que resulta común a todos ellos y por lo mismo su relevancia es de primer orden. Se trata de la burocracia de la Administración pública, cuya importancia en el último franquismo ya he puesto de relieve. La burocracia había hecho posible lo que la monocracia impedía, la circulación social, y ahora posibilitaría también la amalgama política. Ella venía a confundirse con las clases medias fuertemente expandidas, materializaba sus ideales y valores y representaba el nuevo tipo de poder que se estaba gestando, la mesocracia.

Dentro del aparato burocrático generado por el Estado franquista tuvo lugar el que podriamos denominar "primer ensayo de transición", puesto que en él coexistieron prácticamente todos los grupos que iban a estar después presentes en la democracia. En este ámbito se ponen en funcionamiento por primera vez las actitudes y las prácticas típicas de la vida política (disenso, negociación, pactos) y gracias a él se establece el nexo de unión entre ambas formas de sistemas políticos. La burocracia, además, produjo los suficientes intereses (individuales y de grupo) para promover la ruptura pactada antes que el enfrentamiento. Fue, en fin, el vivero de gran parte de los dirigentes del nuevo régimen. Hay que hacer una particular mención, dentro de la Administración, a la Universidad: ella fue el primer escenario político donde se iniciaron y forjaron los líderes del postfranquismo, dado que en ella era donde se toleraba un cierto margen de actividad política.

Debido a esta virtualidades y no sólo a la necesidad de remodelar el vetusto edificio del Estado franquista, las administraciones públicas sufrieron un acelerado proceso expansivo. Con la incorporación a ellas de nuevas cohortes, con su conversión en trampolín de promoción, se ampliaban los incentivos materiales entre la población y se reforzaban los vínculos de adhesión al nuevo estado de cosas. Particularmente signi- 
ficativo para este proyecto de integración de estratos fuertemente aspirativos, ha sido el inusitado desarrollo de las administraciones autonómicas y locales. El análisis más pormenorizado de otras implicaciones políticas, lo he efectuado en un trabajo precedente (Ortega, 1990, cap. 2). En esta ocasión deseo subrayar que la crisis que padecía el Estado heredado del franquismo trató de paliarse ensanchando el círculo de las recompensas a sectores más vastos de la población. Las dificultades de legitimación política propiciaron la aparición de políticas neocorporatistas destinadas a favorecer consensos ampliados. $Y$ así, junto al retorno de las vías parlamentarias de representación, se pusieron en vigor otros cauces políticos más cercanos a los ciudadanos. Es en este diseño donde hemos de encuadrar la generalización del tejido burocrático, en un intento de hacer copartícipe a la sociedad civil (organizaciones, clientes, usuarios, trabajadores y personas individuales) de las decisiones de la política central (C. Offe, 1990). Y ello a pesar del elevado coste económico de tal proyecto, que está haciendo crecer peligrosamente el déficit público.

El partido político que expresaba mejor que ningún otro esta amalgama era la U.C.D. Confluían en su composición todos los factores arriba mencionados y la presencia en él de la burocracia resultaba abultada. Concebido como un partido del poder y desde el poder, era una miscelánea de apetencias, tendencias ideológicas, procedencias variadas y facciones antagónicas. Se trataba, más de que un partido o conglomerado de partidos, de una solución de espera, provisional y por lo mismo transitoria, hasta un acomodo más definitivo (Caciagli, 1986; Huneeus, 1985). Una porción, numéricamente importante, de los cuadros ucedistas no la formaban políticos profesionales, sino altos funcionarios que habían consolidado su posición en el franquismo. Precisamente por esta estructura, la U.C.D. adolecía de la falta de organización interna y de un liderazgo claro. La proliferación de líderes parciales hacian de esta élite un grupo con tendencias centrífugas. Logrado el cambio político y a buen recaudo y salvaguardadas - cuando no incrementadas- las posiciones personales y de grupo, el partido y una parte de sus lideres se derrumbó. La élite del poder centrista, como el partido, fueron de transición.

Por lo que atañe al resto de formaciones políticas(cfr. Gunther, Sani y Sabad, 1986), su con- tribución a la conformación de las clase gobernante fue en este período de menor importancia. El partido abiertamente identificado con el régimen de la dictadura (A.P.) no dejó de ser de reducidas proporciones, y su menguado resultado electoral reflejaba fielmente la pérdida de base y legitimidad social de aquélla. Hasta no desprenderse de su carga nostálgica, esta fuerza política no consiguió tener un respaldo social amplio.

Tampoco desempeñaton el papel al que parecían estar llamados los dirigentes del P.C.E., tan destacado en la oposición al franquismo y con un poderoso sindicato (CC.OO.). Aunque su moderación coadyuvó destacadamente a facilitar la transición, sus líderes dejaron prontamente de tener protagonismo en la élite de poder. Todo ha acontencido, tanto en lo concerniente a A.P. cuanto al P.C.E., como si la proximidad al franquismo -aunque en este caso sea para oponérsele- les hubiese contaminado y distanciado de las expectativas electorales de las nuevas clases medias y trabajadoras.

El partido que, con una base social no muy lejana a la de la U.C.D., representaba mejor que ningún otro a la mesocracia ascendente era el P.S.O.E. Consiguió atraer a su seno, después de la U.C.D., una parte de la burocracia y de las élites potenciales. En los finales del franquismo y durante la transición, esta élite hizo de puente entre los dirigentes socialistas y el resto de la sociedad, sirviendo como canal de información, reclutamiento y generadora de altas aspiraciones promocionales y de cambio (Dowse, Hughes, 1975 , p. 190). Con una amplia y eficaz red de profesionales camuflados (Panebianco, 1990, p. 436), el partido tuvo información privilegiada y la posibilidad de controlar estrechamente al gobierno ucedista, así como contribuir a ahondar un poco más en sus múltiples fracturas internas. Además, gracias a las élites potenciales y a los profesionales camuflados, los socialistas pusieron en su favor a la opinión pública, que depositó en ellos su confianza tras la definitiva entropía ucedista. De este modo, los dirigentes del P.S.O.E y sus élites emergentes se convirtieron, desde la perpectiva que aquí nos importa, no sólo en la alternativa, sino también en la clase dirigente por antonomasia.

Este nuevo marco político se acompaña de un universo cultural en el que se ensalzan los valores colectivos, la solidaridad; hay en el ambiente un cierto clima comunitario y una reducción del ámbito íntimo (descalificado como "pequeño- 
burgués"). Una primera explicación del fenómeno reside en la naturaleza de los acontecimientos: se estaba remodelando la esfera de lo público, después de largos años de haberse impedido intervenir en ella; de ahí la idealización de los objetivos políticos. Otra posible explicación podría hallarse en las tesis de Hirschman (1986, en especial cap. IV), quien sostiene que la decepción generada en el consumo privado conduce como alternativa al foro público. La frustración en esta situación vendría agravada por la prolongada imposibilidad de salir (exii) y alzar la voz (voice) en to asuntos políticos; razón por la que éstos se hacían más deseables. Este paso de lo privado a lo público se corresponde, además, con la nueva posición adquirida por las clases medias, que gracias al desarrolo económico y a las oportunidades burocráticas, habían experimentado un ostensible enriquecimiento dentro de una misma generación. En consecuencia, no sólo atraían las acciones colectivas, sino que bastaba con recibir por ellas incentivos colectivos, simbólicos. Este valor altruista, de desprendimiento tiñó la época de un tono moralista, incluso pedagógico, que casaba mal con el fondo de la vida política, y que sirvió más tarde para el "desencanto" de muchos y el paso al ciclo siguiente, esto es, el del primado de la vida privada.

\section{La consagración de la mesocracia: La vuelta a lo privado}

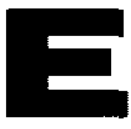

1 triunfo electoral del P.S.O.E. en 1982 culmina el proceso de transición política, y con él se inicia una nueva etapa en la configuración de las élites. Bien es cierto que no implica una ruptura con el período precedente, por cuanto algunas de sus tendencias continuan vigentes ahora, en particular la importante presencia burocrática. Lo que de nuevo tiene el proceso que ahora se inicia es que hay en él una mayor "circulación de élites", ya que nos econtramos ejerciendo la autoridad política a unas clases medias que antes habian carecido absolutamente de ella. Una nutrida representación de las mismas se hallaba entre los cuadros políticos y sindicales socialistas, y nue- vas remesas se irían incorporando al partido y la Administración a medida que se consolidaba la estabilidad electoral socialista.

La estructura ocupacional española en la década de los ochenta se caracterizaba por la fuerte presencia en ella de técnicos, funcionarios superiores, personal administrativo, comerciantes, vendedores y trabajadores de los servicios. Pues bien, en primer lugar, el perfil de los afiliados al P.S.O.E. se correspondía bastante fielmente con aquella estructura, en particular el de los afiliados durante la transición democrática. Para estos, el arribo a la política es más por una ética de la responsabilidad que de la convicción. Esta última quedaba reservada a los militantes históricos. A medida que el mandato socialista se prolongaba, las nuevas remesas de afiliados tenían aun más los rasgos propios de las nuevas clases medias arribistas, gente joven y cualificada con elevadas expectativas de promoción. Pero es que, además, el partido estaba ideológicamente abierto a todas las posibles opciones de la sociedad española: cerca de una tercera parte de sus integrantes eran católicos (Tezanos, 1982).

Si consideramos al electorado en su conjunto, el P.S.O.E. tenía la virtualidad de atraer a sectores de trabajadores y a gran parte de esa clase media a la que podía representar mejor que ninguna otra formación. Sus dirigentes expresaban inmejorablemente la nueva pauta de reclutamiento efectiva entre los estratos intermedios, la meritocracia. Y los criterios de ésta no son otros, como reconoce una obra no lejana a los postulados socialistas, que la competición individual, la privatización de la vida y la búsqueda del logro económico (Giner, 1990, p.40). Justamente esta cultura de clase media será la que ponga en práctica la administración socialista. El problema residía en que la retórica de la propaganda que condujo al triunfo electoral, centrada en la ética, había creado una cierta confusión: se seguía pensando en una moral altruista y colectiva, cuando en realidad los socialistas se referían a esta otra basada en el egoísmo como principio moral. Una conducta regida por el amor propio era el "cambio" prometido, y no otras modalidades más solidarias en que seguían pensando los restos del naufragio izquierdista y sesentaiochista, que dieron su voto al P.S.O.E. en virtud de un sobreentendido o una falsa ilusión.

Hay, por lo demás, otro elemento a considerar. Mientras se es oposición, la tensión generada por un esfuerzo de incierto resultado, se con- 
vierte en una fuente de gratificación. Es ese sentimiento altruista, al que antes me referí, derivado de la autoconvicción de que se particpa en un "combate" noble por elevados objetivos (el bien común, el progreso, la racionalización, la modernización...). Mientras dura este impulso y no hay que evaluar los resultados de la responsabilidad de gobernar, basta con actuar "como sir la sociedad cambiase según nuestros deseos, para creer que el cambio tiene lugar (Hirschman, ibid.). Este fue el sentimiento que embargó a afliados y electores socialistas antes y algunos - pocos- años después del primer triunfo electoral. Y esta fue también una de las principales razones de una cierta frustración entre los militantes y electores más ideologizados. Frustración que no han compartido los típicos electores de clase media, que han seguido votando al P.S.O.E., no porque no hubiese otro partido "menos malo" alternativo (que puede haberlo), sino porque los socialistas estaban llevando a cabo su ideario cultural.

No hay que soslayar tampoco la importancia que el liderazgo juega en las democracias y, por ende, la que ha tenido la dirección socialista. En el caso español, tras la muerte del dictador, desintegrado el partido que había protagonizado ta transición en una estéril batalla interna y privado de toda autoridad y atractivo el presidente Suárez, existía un clima propicio para la aparición de una persona con fuerza política. Como ha escrito Cavalli siguiendo a Weber, en los periodos de transición, para vencer y obtener la disponibilidad del patrocinio económico y social, se eligen hombres de gran personalidad; los viejos cuadros (uidealistas") de los partidos son reemplazados por jóvenes de la nueva clase media ("realistas") que pretenden vivir de la política (Cavalli, Bettin et alii, 1987, pp. 37 ss.). Este papel lo desempeñó F. González, quien indudablemente tenía el suficiente "carisma de situación" como para convertirse en el líder induscutido de la década de los ochenta. Y junto a él, esos otros jóvenes que pertenecían a los sectores más pragmáticos del partido.

En consecuencia, el P.S.O.E. se transforma rápidamente de partido burocrático de masas, fuertemente impregnado de contenidos marxistas y tercermundistas, en un partido catch-all, dirigido a una sociedad más heterogénea y menos antagónica de la prescrita en la vieja estructura partidaria. Acorde con este cambio, los socialistas configuran su partido conforme a nuevas pautas:(1) desideologización (quizá convenga mejor hablar de unanimidad en una sola ideología), con la consiguiente exclusión de tendencias organizadas (en realidad Izquierda Socialista, más que una tendencia ideológica, es un pequeño sector que legitima en su sedicente izquierdismo a los socialistas, al tiempo que otorga a sus miembros un protagonismo dentro del partido que de otro modo no tendrían). (2) Conversión en una organización atenta a los grupos de interés, ya sea a los externos del partido, ya sea reconvirtiendo a diversos estamentos del partido en grupos de interés. Esta es una de las razones principales de la ruptura con el sindicato ugetista y de su vuelco hacia una política más neoliberal que neocorporatista. (3) El debilitamiento de la posición de afiliados y militantes más imbuidos de convicciones y el ascenso de los expertos y técnicos; lo que implica unas relaciones más tibias, cuando no la ausencia de las mismas, con el electorado.(4) El creciente poder del liderazgo, cuya fortaleza depende de dos pilares: el apoyo de los grupos de interés y el mantenimiento de una aceptable imagen pública producida por la comunicación política de masas.(Cfr. al respecto Panebianco, 1990, p.490, y O. Kirchheimer en K. Lenk y F. Neumann, 1980, pp. 33l ss.).

Congruente con estas modificaciones estructurales es que los incentivos selectivos tengan ahora un mayor peso específico, tanto en las relaciones intrapartido como en las de éste con la sociedad; y que por tanto sea este tipo de incentivos el deseado y el otorgado. La participación en la vida pública en virtud de los principios colectivos y altruistas, que predominaban en los primeros tiempos de la transición, resulta ahora de todo punto insatisfactoria. Una sociedad más individualista y valoradora del esfuerzo y de los logros, no puede por menos que provocar dos efectos complementarios en su clase política: En primer lugar, el acrecentamiento de las recompensas materiales en el sector público, y el paso de una parte de los políticos al sector económico privado. Es obvio que ambos resultados se fortalecen mútuamente, ya que el político, sobre todo el técnico pero no sólo él, puede obtener ventajas materiales de su posición de mayor status y mejores cuotas de información; y que por lo mismo su paso al sector privado de la sociedad es siempre tentador al hacerse en términos ventajosos para ambas partes. Es lo que ha dado en denominarse en nuestra sociedad, usando una ex- 
presión que aplicada a los políticos es mera tautología, "tráfico de influencias". La política, por sí sola, no satisface, toda vez que conseguido el acceso a la misma se sacia el deseo previo y simultáneamente se descubren sus limitaciones al comprobar que la realidad no es tan moldeable como la voluntad quisiera. Además, pasado el momento de bisoñez política, la absorbente dedicación que esta actividad requiere resultaría imposible de mantener sin otras compensaciones. Surgen así las dos tentaciones del político ya mencionadas: vivir de la política o especular con la política.

En ambos casos, una nutrida representación de la clase dirigente (de la socialista, que es la mayoritaria, y también de la situada en otras formaciones), ha dado, está dando o a punto de dar el paso de lo público a lo privado. Aparte los beneficios públicos y conocidos que se desprenden del ejercicio de la política, hay, como señala Hirschman (1986, cap. VIII), tres medios principales para este tránsito de clase política a clase económica. El primero de ellos, la corrupción, que sigue a la primera fase de entusiasmo idealista $\mathrm{y}$, por qué no decirlo, algo ilusorio. Una visión más realista lleva a tratar de obtener provecho de las oportunidades ofrecidas por la posición que se ocupa. "Así, pues, la corrupción puede concebirse como una respuesta a un cambio de los gustos; se compensan con ganacias materiales las pérdidas experimentadas en la satisfacción producida por la acción en aras del interés públicon (ibid., pp. 137-38). Mezcla y confusión de asuntos públicos con intereses privados que pueden devolvernos nuevamente al denostado y no superado patrimonialismo del pasado.

En segundo término, la devaluación de los asuntos públicos. Si estos ya no reconfortan y su entrega a ellos se siente como privación, el sistema cultural que ahora se fragua consiste en valores ensalzadores de lo privado. Aparece así una pauta típica de nuestra época: no sólo la crítica constante a los políticos, sino también a las instituciones públicas. La redención y el Edén parecen estar exclusivamente en las organizaciones privadas de la sociedad civil; y el que no puede acogerse a ellas, siempre dispondrá del "refugio" de su propia intimidad. Lo público ha dejado de expresar los aspectos nobles de la acción humana, para venir a ser un ámbito que dignifica poco y mal. Se produce un tipo de conocimiento social en el que la imagen de quien se dedica a asuntos públicos, o trabaja en instancias de ese nivel, aparece en términos negativos, como una persona "que no vale" para otra cosa. Es más, este tipo de dedicación viene a ser a la postre, según la misma crítica, una carga para la sociedad, por lo que se contribuye mejor a la causa pública laborando en pro de los propios intereses personales.

Está por hacerse un análisis detallado y riguroso de la abundante literatura -casi toda ella biográfica- sobre políticos editada en los últimos años. En ella, junto a descripciones físicas que quisieran rescatar a Lombroso, no aparecen sino términos descalificadores: el "conspirador", el "halcón", la «ambición del césar", el wasalto al poder"... Muy otros son los epítetos reservados a banqueros y empresarios de rancio abolengo o cuyo pasado ennoblecido se fraguó en los tiempos del franquismo.

Por último, la magnificencia y deslumbre de las riquezas. El poder puede corromper; la riqueza no, ya que su adquisición y tenencia requieren de elevadas cualidades, tales como la entrega, la humildad, la abnegación y, en fin, la creación de oportunidades y bienestar para los demás. Mientras que buscar y mantener el poder aparece cargado de valencias negativas, crear y atesorar riquezas (siempre y cuando lo sea en el ámbito privado) es objeto de elogio. Se ha ido de este modo tejiendo un auténtica mitología social, plagada de héroes y villanos: estos son siempre políticos, en particular de extracción modesta; aquéllos pertenecen a las cumbres (aunque sean borrascosas) de la riqueza más ostentosa. Tener riqueza se ha convertido en el valor supremo; el problema está en que nunca, o casi nunca, se dice nada de la vía para hacerse rico. Quien ya lo es, tiene los parabienes de esa opinión pública que no es otra que la comunicación de masas (que es de los ya ricos); quien pretende serlo, obtiene todos sus denuestos y reprobaciones.

El fenómeno, por lo demás, no es nuevo o imprevisible. La dominación basada en la legitimidad legal-racional produce, según Weber (194, p. 179), el efecto de plutocratizar la vida social. Y Pareto, en fecha similar, sostiene un planteamiento análogo, sólo que en unos términos, casi como todos los suyos, más radicales y rudos. Según él, plutocracia y democracia van unidas desde fines del XIX, y usi bien, generalmente, especuladores y trabajadores no comparten por completo intereses comunes, ocurre a veces que 
una parte de los unos y otra de los otros encuentran ventajas en obrar en el mismo sentido con el fin de imponerse al Estado y de explotar a las otras clases sociales. Ocurre también que los plutócratas consiguen esta unión por la astucia, aprovechándose de los sentimientos (residuos) de la plebe y enganándola. He aquí cómo aparece en el pueblo y en los empiristas el fenómeno de prudencia llamado la plutocracia demagógican (1985, pp. 65-66).

Es obvio que en este punto, como en algunos más, los gobernantes socialistas han actuado como aprendices de brujo, concitando unas fuerzas que a algunos de ellos rebasan y están a punto de desplazarlos del escenario público. Pero no es menos cierto que los objetivos y valores que acabo de mencionar son todos ellos representativos de las clases medias arribistas, y no sólo de ellas, aunque lo parezca. Lo parece porque en estos estratos es más visible el esfuerzo con alcanzar logros que todavía no se tienen. De ahí que la crítica efectuada por los ya asentados en la clase opulenta, que disfrutan aquéllo que otros aspiran a conseguir, no sólo es hipócrita, sino que entra dentro de los mecanismos de exclusión típicos de todos los poderosos. Sobre todo resulta pintoresco el empeño por deslegitimar a los nuevos ricos, o en trance serlo, por parte de quienes adquirieron tal condición apenas unos lustros atrás. La lectura de Veblen se torna en nuestros tiempos una tarea de higiene mental y moral colectiva, si es que se quiere entender cuanto sucede en nuestro entorno; al menos un poco más de lo que da a entender la fenomenología periodística al uso.

Este conjunto de factores ha convertido, en nuestra época posiblemente más que en ninguna otra, el dinero en el bien duradero más deseado. Ciertamente porque a diferencia de otros bienes, el dinero tiene un carácter abstracto que impide su consunción y pocas veces defrauda, como atinadamente ya viese Simmel. Pero, además, en unos tiempos de consumo generalizado y patrones culturales bastantes homogeneizados, es el único signo de distinción que queda para alejar a los poderosos de la "cultura de medio pelon accesible a las masas. Y donde mejor cumple este signo con su función de comunicar distinción, es en aquellos estratos recién promocionados, que perentoriamente lo necesitan para ocultar o negar sus orígenes y alejarse de los círculos que frecuentaron en su época de mayor bisoñez.

\section{La circulación de las élites y sus límites}

a transición política primero y fundamentalmente la llegada al poder del P.S.O.E. después, han supuesto una renovación importante de la clase dirigente española. Al menos ha habido tres procesos complementarios de cambios en la misma: (i) desaparición de una parte y reconversión de otra de la vieja clase franquista; (ii) relevo generacional, y (iii) formación de una nueva clase en sentido estricto. Sin duda alguna, los sectores del franquismo más fundamentalistas han desaparecido del escenario político. Mientras que aquellos grupos (oportunistas) que colaboraron en los últimos tiempos con el viejo régimen pero lo hicieron siempre desde posiciones ambiguas, perviven en élites de la democracia, algunos jugando un destacado papel. También ha dejado de ser clase dirigente una parte importante de la clase económica del franquismo, desplazada por las diversas crisis económicas (en particular la bancaria) y reconversiones del aparato económico.

El segundo gran proceso de transformación es más aparente que real: se trata simplemente del relevo debido a la edad. Incluyo aqui a los descendientes de sagas y linajes que siempre dispusieron de un recambio para cualquier opción política; familias de acendrado franquismo que dieron vástagos a la U.C.D, al P.P. (antes A.P.), al P.S.O.E. y al P.C.E.; e incluso a otras formaciones más extremosas. La capacidad de transfiguración política de estas líneas de parentesco es más rápida que el propio relevo generacional. Sus redes de intereses y familiares se confunden, y sus conexiones e influencias son tan amplias que les permiten una animada e intensa circulación por todo el espectro político. Y cuando falla la política, es fácil recurrir al patrimonio familiar o al del Estado. Algunas de estas sagas son anteriores al período republicano; otras son de fecha más reciente y deben su fortaleza a la posición que supieron apropiarse tras la victoria nacionalista en la contienda civil.

La constitución de una nueva clase dirigente $y$, por ende, la circulación de las élites en sentido estricto, plantea algunas dificultades reales y analíticas. Estamos en presencia de un grupo heterogéneo, en el que se incluyen también segmentos de los otros sectores que acabo de men- 
cionar, aunque no sea simepre fácil aislarlos. El rasgo çcomún de esta nueva clase es que debe su actual posición a la vía política seguida. Es la política la variable más significativa en la configuración del grupo. Y es en virtud de ella como han tenido acceso a otras oportunidades, principalmente económicas. Para la mayoría de ellos, habrian resultado inalcanzables la preeminencia social y los recursos materiales brindados por la acción pública, debido a sus orígenes de clase media. Es por tal razón por la que es vista como una clase arribista, y como tal se comporta; es decir, como nuevos ricos que han de hacer alarde y ostentación de los bienes recién logrados. Carecen, todavía, de la solera y reposo de la riqueza sedimentada.

Ahora bien, ¿es la carrera política una variable independiente capaz de explicar la génesis de las clases dirigentes?. Mi hipótesis es que lo es, pero sólo para cortos períodos temporales caracterizados por el tránsito político de un régimen a otro; pero esta variable por sí sola no es el criterio único de selección de la élite, ya que va acompañada de otras variables intervinientes que son extraordinariamente poderosas: la meritocracia y la adscripción económico-familiar. Son esta variables, además, las que en períodos de normalidad democrática se convierten en las realmente independientes, siendo la política mera interviniente. La política, sin más, cuenta poco. Es decir, el partido político desempeña un restringido papel de cambio en las élites y de movilidad social en los períodos de estabilidad política. La razón de este fenómeno es doble. Una es intrínseca a la propia política deomcrática: la volatilidad electoral y la provisionalidad de todo cargo político, hacen preferibles otras vías para ascender socialmente. La otra es extrínseca al funcionamiento político y tiene que ver con la estratificación: el cierre social se establece para impedir el paso a quien, aun contando con una buena posición estratégica, carece por sus origenes y background de los dones y méritos idóneos. De ahí que aunque en ocasiones pueda ser necesario, no es suficiente, para pertenecer y mantenerse en la clase gobernante, con disponer del apoyo del aparato de un partido político.

Así pues, la política, que había seguido como mecanismo de promoción típico de las clases medias a la burocracia, ha dejado de ser, al menos en nuestra sociedad, autosuficiente. Requiere, para tener alguna validez, de prerrequisitos estructurales que devuelven a la concreta confi- guración del orden social. De manera que más que hablar de circulación de las élites tenemos que hacerlo de circulación entre las élites. La reducida movilidad social y la insuficiencia de la política ponen de relieve que la democracia española ha entrado en una fase de oligarquización relativamente estable.

Dicho esto, conviene añadir de inmediato que la política contribuye activamente a mejorar la posición de aquellos que cuentan con los adecuados requisitos meritocráticos. Se trata, en este caso, de los que podriamos denominar políticos camuflados: si intervienen en el escenario público o dedican alguna atención a la política (por ejemplo militando en algún partido) es para mejorar su carrera profesional dentro del aparato administrativo. Es una de las manifestaciones del tipo especulador que, para usar los mismos términos paretianos, se basa en el residuo de las "combinaciones", y cuyo objetivo es el incremento personal de la riqueza, en detrimento de cualquier otra consideración sobre la moral y los intereses públicos. Dentro de este tipo, hay dos modalidades: (1) el político-negociante, que persigue obtener, a través de cauces políticos, una posición económico-empresarial que de otra manera no habría logrado. (2) El políticoparásito, que se enquista en el aparato administrativo y lo usa para el medro y la carrera personal dentro de él. Este subtipo representa a la nueva clase patrimonialista generada al amparo de la democracia.

A todos ellos hay que añadir un último componente de la élite política, por lo demás presente en todas las sociedades y partidos democráticos: el técnico o profesional, que vive transitoriamente de la política, y que no requiere ni de la maquinaria partidista ni de imagen pública para fortalecer un perfil profesional que se ha construido previamente. Fundada su legitimidad en el criterio de la eficacia, su papel responde mejor a la sociedad corporativa en que nos encontramos actualmente. El deterioro del hombre público, la ley de hierro de las burocracias partidistas y la fragilidad de la notoriedad política, están llevando, si bien no de forma lineal y simple, a la aparición de un político de nuevo cuño y que se define en términos contradictorios: dedicarse a algo que no es. $\mathrm{El}$ proceso está más avanzado en otras partes (cfr. Cavalli, Bettin et alii, 1987), pero también ha prendido entre nosotros. La era de la tecnocracia ha retornado.

Pero una tecnocracia que no puede existir 
más que a condición de tener a su frente un líder con carisma . La única forma de inducir al voto y provocar una cierta adhesión (cuando no movilización) social en las masas electoras, de legitimar las prácticas políticas neoliberales o neocorporatistas, no es otra que situar en la cúspide a un político con buena imagen mass-mediática. Por ello mismo, algunas de las grandes batallas no se libran, aunque no pueda prescindirse de ellas, en las organizaciones partidistas, sino en la comunicación política. Es en este ámbito de la comunicación al que han de acudir quienes aspiran al liderazgo social. Razón por cual progresivamente el rol típico del político es desempeñado cada vez menos por los políticos y más por los periodistas (Ortega, 1992b). Pero decir periodismo es lo mismo que referirse a corporaciones oligopolistas. A ellas se ha transferido una gran parte de las funciones que formalmente tienen atribuidas las asambleas representativas: responsabilidad, control y selección de los políticos (Weber, 1944, p. 1095). Esta última función, si bien legalmente la ejercen los parlamentos, está precedida por la producción de personajes públicos notorios debida a las industrias de la conciencia o medios de masas.

De modo que la clase política tiende hoy a estar integrada por dos tipos de personajes: los líderes, que son preseleccionados por dos grandes organizaciones corporativas (Prensa y Partidos), y los técnicos, que obedecen a las necesidades de los diversos grupos de intereses en que se apoyan aquellas organizaciones. El resto forma parte de las rutinas propias del sistema democrático, que las requiere para hacer creible su fundamento, pero que políticamente resultan inanes.

\section{BIBLIOGRAFIA}

Beltran, M., La élite burocrática española, Barcelona, Ariel, 1977.

CACIAGLI, M., Elecciones y partidos en la transición española, Madrid, CIS, 1986.
Cavalli, L. y G. Bettin et alii, Leadership e democrazia, Padova, Cedam, 1987.

Costa, J., Oligarquia y caciquismo, Madrid, Ministerio de Trabajo, 1976, 2 vols.

DAHL, R.A., La poliarquía, Madrid, Tecnos, 1990.

Dahrendorr, R., Las clases sociales y su confficto en la sociedad industrial, Madrid, Rialp, 1974.

Dowse, RE. y Hughes, J.A., Sociologia política, Madrid, Alianza, 1975.

ELías, N., El proceso de la civilización, Madrid, FCE, 1987.

Giner, S.(dir.), España. Sociedad y Politica, Madrid, Espasa, 1990.

Gunther, R.; Sani, G., y Shabad, G., El sistema de partidos políticos en España. Génesis y evolución, Madrid, CIS, 1986.

HiRschman, A.O., Interés privado y acción pública, México, FCE, 1986.

Huneeus, C., La Unión de Centro Democrático y la transición a la democracia en España, Madrid, CIS, 1985.

JEREZ, M., Elites políticas y centros de extracción en España 1938-1957, Madrid, CIS, 1982.

Kagan, R.L., Universidad y Sociedad en la España Moderna, Madrid, Tecnos, 1981.

Lenk, K. y Neumann, F. (eds.), Teoria y sociología críicas de los partidos politicos, Barcelona, A nagrama, 1980.

LiNZ, J.J., "Transiciones a la democracia", R.EI.S., n 51 , 1990.

Maravall, J.A., Poder, honor y élites en el siglo xwi, Madrid, Siglo XXI, 1979.

Mastellone, S., Historia de la democracia en Europa, Madrid, Edersa, 1990

Miguel, A. de, Sociología del franquismo, Barcelona, Euros, 1975 .

NieTo, A., La organización del desgobierno, Barcelona, Ariel, 1984.

OfFE, C., Contradicciones en el Estado de Bienestar, Madrid, Alianza, 1990.

Ortega, F., Las contradicciones sociales de la modernización, Madrid, Edersa, 1990.

Ortega, F. "Orden político y modernización social en Españan, Revista Mexicana de Ciencias Politicas y Sociales, $3^{\text {a }}$ época, $\mathrm{n}^{\circ}$ 9, 1992a.

Ortega, F., "Los nuevos intelectuales orgánicos", Claves de razón práctica, $\mathrm{n}^{\circ} 24,1992 \mathrm{~b}$.

Ortega y Gasset, J., España invertebrada, Revista de Occidente, 1988. (1"a ed. 1922)

Paneblanco, A., Modelos de partido, Madrid, Alianza, 1990.

Pareto, V., La transformación de la democracia, Madrid, Edersa, 1985.

Tezanos, J.F., Sociología del socialismo español, Madrid, Tecnos, 1982.

Varela Ortega, J., Los amigos políticos, Madrid, Alianza, 1977.

Weber, M., Economía y Sociedad México, FCE, 1944, 2 vols. 